03

\title{
Исследование теплообмена при конденсации на поверхностях труб методом градиентной теплометрии
}

\author{
() С.З. Сапожников, В.Ю. Митяков, А.В. Митяков, А.Ю. Бабич, Э.Р. Зайнуллина \\ Санкт-Петербургский политехнический университет Петра Великого, Санкт-Петербург, Россия \\ ฯ E-mail: zaynullinaelza@gmail.com
}

Поступило в Редакцию 19 ноября 2018г.

В окончательной редакции 20 декабря 2018 г.

Принято к публикации 28 декабря 2018г.

\begin{abstract}
Теплообмен при конденсации впервые изучен с помощью градиентной теплометрии. Применимость нового метода проверена на модели хорошо изученного объекта - круглой трубы. Экспериментальное исследование включало изучение теплообмена при конденсации насыщенного водяного пара на наружной и внутренней поверхностях трубы. Выявлена высокая информативность градиентной теплометрии, открывающая новые возможности для исследований в области теплообмена при фазовых превращениях.
\end{abstract}

DOI: 10.21883/PJTF.2019.07.47529.17600

Изучение теплообмена при конденсации важно для улучшения технико-экономических параметров ТЭС, повышения безопасности АЭС, совершенствования конденсаторов энергетических и холодильных установок, внедрения новых рабочих тел и др. К настоящему моменту сформировалась обширная база экспериментальных исследований теплообмена при конденсации, большинство из которых выполняется посредством термометрии [1-4]. Эти эксперименты не обеспечивают требуемой достоверности результатов, поскольку термометрия позволяет рассчитывать лишь осредненные по времени значения плотности теплового потока и коэффициента теплоотдачи. Такой подход не позволяет описать нестационарность теплообмена, формирование волн на конденсаторной пленке и пр. В настоящей работе предложен новый метод исследования теплообмена при конденсации - градиентная теплометрия, основанная на применении градиентных датчиков потока (ГДТП) [5]. ГДТП представляют собой тонкие пластинки с анизотропией электро- и теплофизических свойств. При прохождени теплового потока через ГДТП возникает термоэдс, обусловленная поперечным эффектом Зеебека и пропорциональная плотности теплового потока и площади датчика. Уникально малая постоянная времени ГДТП $\left(10^{-8}-10^{-9} \mathrm{~s}\right)$ позволяет считать их практически безынерционным средством измерения и дает возможность отслеживать колебательные процессы при конденсации. В опытах применялись гетерогенные градиентные датчики теплового потока (ГГДТП), выполненные на основе композиции сталь $12 \mathrm{X} 18 \mathrm{H} 9 \mathrm{~T}+$ никель, с вольт-ваттной чувствительностью $0.008 \mathrm{mV} / \mathrm{W}$. Поскольку чувствительность ГГДТП зависит от температуры, датчики подключались по трехпроводной схеме: по медным проводам передавался сигнал ГГДТП, а пара медь-константан фиксировала текущую температуру датчика в ходе опыта.
Сигнал ГГДТП, пропорциональный тепловому потоку, получается в ходе прямого измерения, поэтому важно убедиться в его достоверности. Мы использовали подход и терминологию действующего в Российской Федерации ГОСТ 34100.1-2017, согласно которому понятие ошибки измерения заменено существенно иным понятием неопределенности. Неопределенность теплометрии оценивалась в ходе градуировки на специально созданном стенде. Неопределенность оценки коэффициентов теплоотдачи зависела от методики опытов и расчетов; она заведомо выше, чем для теплометрии.

В качестве объекта исследования выбрана круглая труба, теплообмен при конденсации на поверхностях которой хорошо изучен как теоретически, так и экспе-

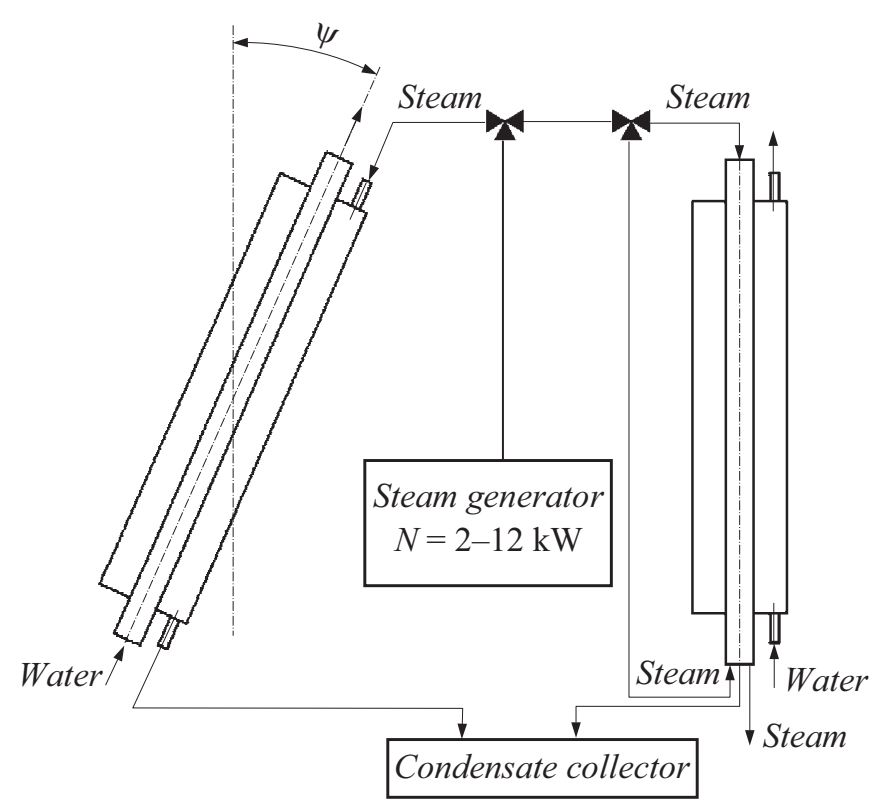

Рис. 1. Схема экспериментальной установки. 


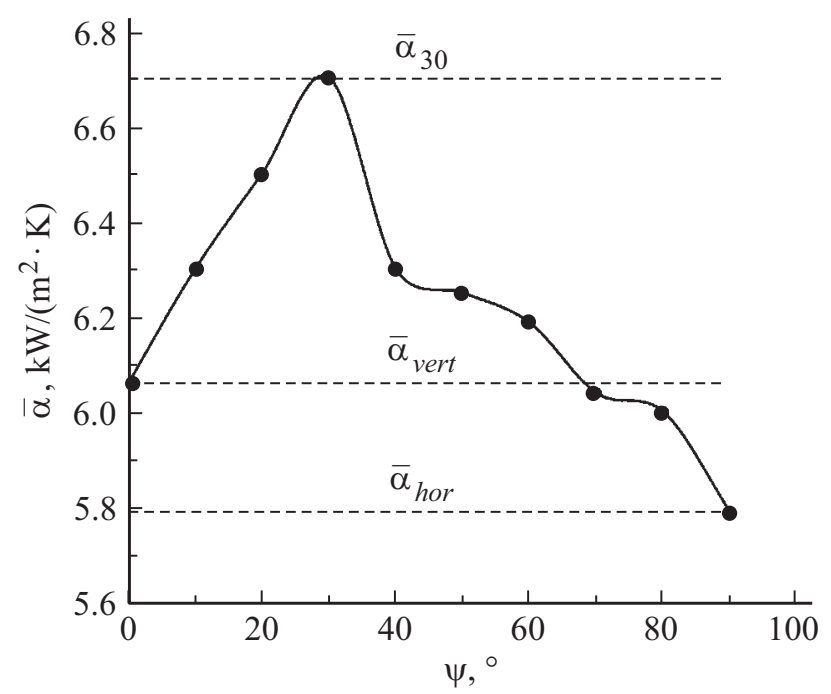

Рис. 2. Зависимость среднего коэффициента теплоотдачи $\bar{\alpha}$ от наклона трубы. $\bar{\alpha}_{30}-$ наклон на угол $\psi=30^{\circ}$ от вертикали, $\bar{\alpha}_{v e r t}-$ без наклона, $\bar{\alpha}_{h o r}$ - в горизонтальном положении.

риментально. Исследован теплообмен при конденсации на внешней и внутренней поверхностях трубы.

На рис. 1 представлена схема эксперимента. При изучении теплообмена на наружной поверхности трубы, выполненной из нержавеющей стали (длина трубы $h=1200 \mathrm{~mm}$, наружный диаметр $d_{1}=20 \mathrm{~mm}$, толщина стенки $\delta=2.5 \mathrm{~mm}$ ), среды двигались в противотоке: водопроводная вода подавалась внутрь металлической трубы при температуре $t_{\mathrm{H}_{2} \mathrm{O}}=22^{\circ} \mathrm{C}$, насыщенный водяной пар с температурой насыщения, близкой к $100^{\circ} \mathrm{C},-$ в соосный с трубой кожух. Датчики монтировались заподлицо с наружной поверхностью трубы.

Формула Нуссельта позволяет рассчитать средний коэффициент теплоотдачи при конденсации на вертикальной и горизонтальной трубах. Значения коэффициента теплоотдачи, полученные в эксперименте, отличаются от рассчитанных по формуле Нуссельта на $2-5 \%$, что подтверждает применимость градиентной теплометрии для исследования теплообмена при конденсации.
Известно [6,7], что отклонение трубы от вертикали интенсифицирует теплообмен на ее наружной поверхности. Возможность интенсифицировать теплообмен отклонением трубы проверена в серии опытов, где трубу удалось как наклонять, так и поворачивать вокруг собственной оси, получая распределение плотности теплового потока по периметру.

Исследования показали, что при отклонении трубы от вертикали на угол $\psi=30^{\circ}$ коэффициент теплоотдачи максимален и превышает значения, полученные на вертикальной трубе, на $10.5 \%$ (рис. 2). При отклонении трубы от вертикали на $10-60^{\circ}$ средний коэффициент теплоотдачи также выше, чем для вертикальной трубы. Относительная неопределенность измеренной плотности теплового потока не превысила $9 \%$, а рассчитанного коэффициента теплоотдачи $-12 \%$.

При исследовании конденсации на внутренней поверхности трубы рабочий участок состоял из двух коаксиальных труб: внутренняя выполнена из нержавеющей стали $\left(h=1200 \mathrm{~mm}, d_{1}=20 \mathrm{~mm}\right.$, толщина стенки $\delta=2.5 \mathrm{~mm})$, а наружная - из пластика. Пар с температурой насыщения, близкой к $100^{\circ} \mathrm{C}$, подавался в металлическую трубу, а охлаждающая вода при температуре $t_{\mathrm{H}_{2} \mathrm{O}}=22^{\circ} \mathrm{C}-$ в межтрубное пространство. Регулировался расход пара и охлаждающей воды, менялись направления сред.

Как и в большинстве промышленных конденсаторов, пар подавался из парогенератора мощностью $12 \mathrm{~kW}$ в трубу сверху, а охлаждающая вода в межтрубное пространство - снизу. Отличие полученных в эксперименте коэффициентов теплоотдачи от рассчитанных по формуле Нуссельта не превышало 7\%.

Исследовано противо- и сонаправленное движение пара и охлаждающей воды. В качестве примера на рис. 3 представлены временнб́е теплограммы, полученные при сонаправленном движении сред и мощности парогенератора $7 \mathrm{~kW}$. В этих опытах попеременно устанавливались режим обратной конденсации и пробочный режим. При пробочном режиме $(\tau \approx 200-400 \mathrm{~s})$ плотность теплового потока на первом от верхней кромки ГГДТП минимальна: пробка блокировала поступление пара в верхнюю часть трубы. При движении пробки вверх

$a$
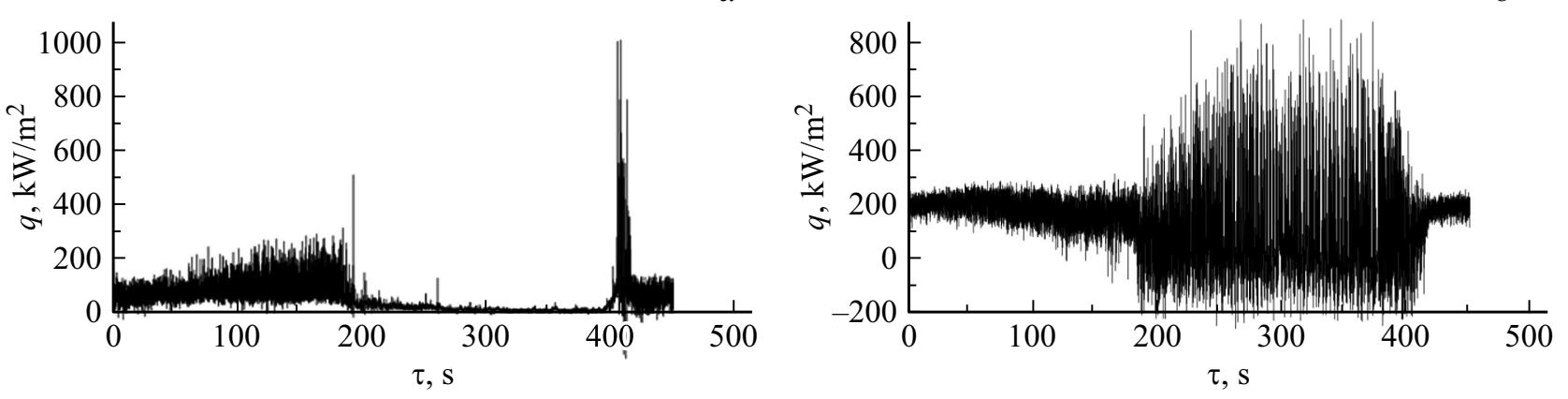

Рис. 3. Временнб́е теплограммы при сонаправленном движении сред и мощности парогенератора $7 \mathrm{~kW}: a-$ ГГДТП № 1 $(x=300 \mathrm{~mm}$ - расстояние от верхней кромки $), b-$ ГГДТП № $4(x=900 \mathrm{~mm})$. 
ГГДТП реагировали один за другим, что подтвердило их высокое быстродействие. После выброса пробки на некоторое время снова устанавливался режим обратной конденсации. Переход от режима к режиму сопровождался колебаниями пробки конденсата; скорость пробки достигала $2 \mathrm{~m} / \mathrm{s}$. Относительная неопределенность результатов составила $10.3 \%$.

Таким образом, показана применимость градиентной теплометрии на основе гетерогенных градиентных датчиков теплового потока для исследования теплообмена при конденсации. Результаты свидетельствуют о высокой информативности нового метода. Опыты позволили отследить смену режимов течения конденсатной пленки и определить оптимальный угол отклонения трубы от вертикали.

Применение градиентной теплометрии для исследования теплообмена при конденсации на наружной поверхности трубы позволяет получить данные, необходимые для оптимизации теплообменников энергетических и холодильных установок: информация о расположении поддонной зоны позволит определить наилучшее место установки поверхностных интенсификаторов. Исследования теплообмена при конденсации на внутренней поверхности трубы и их результаты необходимы при предотвращении и ликвидации последствий ядерных и других техногенных аварий. Полученные результаты свидетельствуют о том, что уникальное быстродействие ГГДТП позволяет применять их как средство мониторинга теплообмена при конденсации на АЭС и ТЭС, что повысит их безопасность.

\section{Список литературы}

[1] Kim S.J., No H.Ch. // Int. J. Heat Mass Transfer. 2000. V 43. P. 4031-4042.

[2] Lee K.-W., No H.Ch., Chu I.-Ch., Moon Y.M., Chun M.-H. // Int. J. Heat Mass Transfer. 2006. V. 49. P. 1813-1819.

[3] Fan G., Tong P., Sun Z., Chen Y. // Ann. Nucl. Energy. 2018. V. 113. P. 139-146.

[4] Hu H.W., Tang G.H., Niu D. // Appl. Therm. Eng. 2016. V. 100. P. 699-707.

[5] Сапожников С.З., Митяков В.Ю., Митяков А.В. Основы градиентной теплометрии. СПб.: Изд-во Политехн. ун-та, 2012. $215 \mathrm{c}$.

[6] Nada S.A., Hussein M.S. // Int. J. Therm. Sci. 2016. V. 100. P. $391-400$

[7] Lips S., Meyer J.P. // Int. J. Heat Mass Transfer. 2012. V. 55. P. 395-404. 